\title{
Impact of interventions to prevent and manage preeclampsia and eclampsia on stillbirths
}

Mehnaz Jabeen, Mohammad Yawar Yakoob, Aamer Imdad, Zulfiqar A Bhutta*

\begin{abstract}
Background: Pre-eclampsia and Eclampsia are relatively common complications of pregnancy, leading to considerable maternal and fetal mortality and morbidity. We sought to review the effect of aspirin, calcium supplementation, antihypertensive agents and magnesium sulphate on risk stillbirths.
\end{abstract}

Methods: A systematic literature search was conducted to identify studies evaluating the above interventions. We used a standardized abstraction and grading format and performed meta-analyses where data were available from more than one studies. The estimated effect on stillbirths was determined by applying the standard Child Health Epidemiology Reference Group (CHERG) rules for multiple outcomes. For interventions with insufficient evidence for overall effect, a Delphi process was undertaken to estimate effectiveness.

Results: We identified 82 relevant studies. For aspirin, maganesium sulphate and use of antihypertensive we found an insignificant decrease in stillbirth and perinatal mortality. For calcium supplementation, there was a borderline significant reduction in stillbirths (RR 0.81, $95 \% \mathrm{Cl}$ 0.63-1.03). We undertook a Delphi consultation among experts to assess the potential impact of a package of interventions for the management of pre-eclampsia and eclampsia (antihypertensive, magnesium sulphate and C-section if needed). The Delphi process suggested 20\% reduction each in both antepartum and intrapartum stillbirths with the use of this package.

Conclusions: Despite promising benefits of calcium supplementation and aspirin use cases on maternal morbidity and eclampsia in high risk cases, further work is needed to ascertain their benefits in relation to stillbirths. The Delphi process undertaken for assessing potential impact of a package of interventions indicated that this could be associated with $20 \%$ reduction in stillbirths, for input into LiST.

\section{Background}

Hypertensive disease of pregnancy (HDP) is one of the most common complications of pregnancy, occurring in $5-8 \%$ of the pregnancies [1]. Hypertensive disorders are the second most common cause of maternal deaths worldwide [2]. There are several major categories of hypertensive disorders in pregnancy ranging from mild to moderate rise in blood pressure without proteinuria [usually called pregnancy induced hypertension (PIH)], preeclampsia (hypertension with proteinuria), severe preeclampsia and eclampsia [3]. Maternal hypertension, even of the mild to moderate category, can lead to adverse perinatal outcomes like low birth weight, prematurity, stillbirth and intrauterine growth retardation [4]. A population-based study of 57 million singleton

\footnotetext{
* Correspondence: zulfiqar.bhutta@aku.edu

Division of Women \& Child Health; The Aga Khan University, Stadium Road, P.O. Box 3500, Karachi-74800, Pakistan
}

live- and stillbirths has shown that pregnancy induced hypertension (PIH) is associated with increased risk of stillbirth and neonatal mortality [5]. The risk of stillbirth was higher in women having their second or higher order births [(Odds Ratio (OR) $=2.24$, 95\% confidence interval $(\mathrm{CI})=2.11-2.37)]$ compared with women having their first birth (OR=1.52, 95\% CI=1.40-1.64).

Detection and prevention of maternal hypertensive disorders is important in order to avoid morbidity and mortality associated with them [6]. Potential interventions for reducing the risk of preeclampsia include calcium and aspirin used for prevention and use of anti-hypertensive drugs and magnesium sulphate for management of preeclampsia/eclampsia. A $17 \%$ reduction in the risk of preeclampsia was noted with the use of antiplatelet agents - mostly low dose aspirin - in pregnant women at risk of preeclampsia (RR $0.8395 \%$ CI 0.77-0.89) [7]. A Cochrane review [8] that included 13 randomized trials 
comprising 15,730 women has shown that calcium supplementation during pregnancy reduces the incidence of preeclampsia by $55 \%$ [Relative risk $(\mathrm{RR})=0.4595 \%$ confidence interval (CI) $0.31-0.65]$ and that of gestational hypertension by $35 \%$ [RR=0.65, $95 \%$ CI $0.53-0.81]$. The reduction in the risk of preeclampsia was greatest for women at high risk of developing preeclampsia (RR 0.22, 95\% CI 0.12-0.42), and for those with low baseline intake of calcium (RR $0.36,95 \%$ CI $0.20-0.65$ ). A variety of antihypertensive agents including beta-blockers like labetalol $[9,10]$, atenolol [11,12], oxeprenolol [13]; calcium-channel blockers like isradipine [14], nifedipine [15,16]; and other antihypertensive drugs like methyldopa (an alpha-blocker) [17-19] have been shown to be effective in controlling blood pressure during pregnancy. Magnesium sulphate (MgSO4) supplementation has been shown to be effective for prevention of eclampsia in pre-eclamptic women [20]. A Cochrane review [21] that included six trials for $\mathrm{MgSO} 4$ analysis has shown that compared with placebo or no anticonvulsant, $\mathrm{MgSO} 4$ reduced the risk of eclampsia by $59 \%$ [RR $0.41,95 \%$ CI 0.29 to 0.58 ].

The purpose of this paper was to review the effect of calcium supplementation, aspirin, antihypertensive agents, and magnesium sulphate on stillbirths and perinatal mortality related to maternal hypertensive disorders. This paper is a part of series of papers for the Lives Saved Tool (LiST). The process of generating a point estimate for efficacy of an intervention involves qualitative evaluation of available evidence according to Grading of Recommendations, Assessment, Development and Evaluation (GRADE) criteria [22] and quantitative measure according to Child Health Epidemiology Reference Group (CHERG) rules [23]. For more details of the review methods, the adapted GRADE approach or the LiST model see the methods paper [23] and other articles in this supplement.

\section{Methods}

We systematically reviewed all published literature from 1957 to June 2010 to identify studies that reported the effect of calcium supplements, aspirin, antihypertensive drugs or magnesium sulphate on stillbirths and perinatal mortality as outcomes amongst pregnant women. As per CHERG guidelines [23], we searched PubMed, the Cochrane Library and all WHO regional databases and included publications available in any language [23].

Two search strategies were used as follows:

1) (aspirin OR antiplatelet OR antihypertensive* $O R$ "beta-blocker"" OR "calcium channel blocker" OR "alpha-blocker" OR "magnesium sulphate") AND (pregnancy or maternal) AND (stillbirth" OR "perinatal mortality" OR "fetal death" OR eclampsia OR "severe preeclampsia" OR "intrauterine death" OR "preeclampsia" OR" preeclampsia*).
2) "Calcium" AND "pregnancy" AND ("Hypertension" OR "preeclampsia" OR "blood pressure" OR "Stillbirth" OR "Intrauterine death").

Every effort was made to gather unpublished data when reports were available for full abstraction. Previous reviews were also hand-searched for relevant studies not picked up in the primary literature search [3,24-26]

\section{Inclusion/exclusion criteria}

We included randomized and quasi-randomized controlled trials that evaluated the following as an intervention: calcium supplements, aspirin with or without other antiplatelet agents, antihypertensive agents of any category, and magnesium sulphate. Studies were included if they had an identical control group that was given either placebo or no treatment. The studies were selected irrespective of the dose used. For calcium, only those studies were included in which baseline calcium intake of participants was low as calcium supplementation during pregnancy is effective only in population with low calcium intake. We excluded any studies reporting only before-after comparisons as well as observational studies and in addition we excluded those studies that did not report outcomes of interest for this review.

\section{Abstraction, analysis, and summary measures}

All studies that met the final inclusion and exclusion criteria were double-data abstracted into a standardized form for each outcome. We extracted the data for study design; location; population; methods; limitations; assessment of blinding, allocation concealment; and outcomes of interest. Each study was assessed and graded according to the CHERG adaptation of the GRADE technique. Each study was assigned a final quality grade of "high" "moderate" "low" or "very low" on the basis of strengths and limitations of study [22,23]. Studies receiving a grade of 'very low' were excluded from the analysis. The grading of overall (pooled) evidence was based on three components: (1) the volume and consistency of the evidence; (2) the size of the pooled effect and (3) the strength of the statistical evidence reflected in the p-value [23]. A similar grading of 'high' 'moderate' 'low' and 'very low' was used for grading the overall evidence indicating the strength of an effect of the intervention on specific health outcome [23]

We undertook meta-analyses where data were available from more than one study for an outcome and reported Mantel-Haenszel pooled relative risks and corresponding $95 \%$ confidence intervals. The primary outcome of interest was stillbirth. Statistical heterogeneity in the pooled data was assessed by visual inspection of overlap of confidence intervals and P-value $(\mathrm{P}<0.10$ was taken to mean substantial heterogeneity). 
The assessment of statistical heterogeneity in the pooled analysis was done by visual inspection i.e. the overlap of the confidence intervals among the studies, Chi square (P-value) of heterogeneity in the meta-analyses and $\mathrm{I}^{2}$ statistics. A low $\mathrm{P}$ value (less than 0.10 ) or a large chi-squared statistics relative to its degree of freedom and $\mathrm{I}^{2}$ values greater than $50 \%$ were taken as substantial and high heterogeneity. In situations of substantial or high heterogeneity being present, causes were explored by sensitivity analysis and random effects model were used.

\section{Results}

We identified 2069 titles from the first search strategy and 1022 titles from the second, in searches conducted in databases including PubMed and the Cochrane Library (Figure 1). After initial screening of these titles and abstracts, we reviewed 121 papers to identify outcomes of interest and included 82 papers in the final database. All the included studies were blinded, randomized, controlled treatment trials. The detailed data extraction with the limitation of studies is shown in Additional File 1. In tables 1, 2, 3, 4, we report the quality assessment of studies of each intervention by outcome, as well as results from corresponding meta-analyses.

\section{Aspirin in high-risk pregnancy}

To estimate the effect of aspirin in high-risk pregnancies for prevention of preeclampsia, we found 21 studies which reported data on the effect of aspirin alone on stillbirths [1,4,9,12,13,15-19,27-37] and 3 studies reporting combined effects of aspirin and diypyramidole on stillbirths [38-40]. A total of 13 studies reported perinatal mortality $[1,4,15,17,27,29,31,33,35,36,39,41-43]$ (Table 1). The effect of aspirin alone showed no significant effect on risk of stillbirths ( $R R=1.15 ; 95 \%$ CI: 0.88 to 1.49$)$ (Figure 2). Combining studies of aspirin with dipyramidole with aspirin alone yielded similar results $(R R=1.06$; 95\% CI: 0.82 to 1.37 ).

\section{Calcium supplementation in low-intake population}

To estimate the effect of calcium supplementation in pregnant women in low-intake population, we found 3 studies which reported data on stillbirths, [55-57] and 4 studies which reported perinatal mortality (Table 2). Our analysis suggested that calcium supplementation during pregnancy could potentially reduce stillbirths by $19 \%$, however results were not statistically significant (RR 0.81, $95 \%$ CI 0.63-1.03) (Figure 3). These data suggest the need for further large scale studies of calcium supplementation in populations with specific assessment of stillbirth outcomes.

\section{Antihypertensive agents in pregnancy with mild to moderate hypertension}

To estimate the effect of antihypertensive agents in pregnant women with mild to moderate hypertension, we found 18 studies which reported data on stillbirths $[10,14,58-73]$ and twenty studies which reported data on perinatal mortality $[14,58,60,61,63-66,68,69,71-80]$ (Table 3).The effect of antihypertensive drugs showed no effect for stillbirths ( $R R=1.14 ; 95 \%$ CI: 0.60 to 2.17$)$ (Figure 4).

\section{Magnesium sulphate in pregnancy with preeclampsia}

To estimate the effect of magnesium sulphate for pregnancies with preeclampsia versus placebo or no treatment, we found 3 studies which reported data on stillbirths [82-84], 2 studies which reported perinatal mortality $[82,83]$ (Table 4). There was no impact of use of magnesium sulphate on stillbirths $(\mathrm{RR}=0.99$; $95 \% \mathrm{CI}$ : 0.87 to 1.12 ) (Figure 5).

\section{Delphi process for establishing expert consensus}

As there was no convincing evidence in favor or against of use of antihypertensive and magnesium sulphate with respect to stillbirths, we sought expert consensus via the Delphi method [23]. The panel invited to participate were experts belonging to six WHO regions (South Asia, Africa, Western Europe, Eastern Europe, North America, and Australia) and a range of disciplines including maternal health, public health, obstetrics/gynecology, and midwifery. 33 experts agreed to participate in the Delphi process. The questionnaire was developed by MYY and $\mathrm{ZAB}$, and refined after several rounds of pilot testing. The questionnaire was sent by email and included the background and aims of the Delphi and estimates of effect that were available from the literature for different scenarios. The median response and range were determined for each question. Consensus was defined a priori as an interquartile range in responses of not more than $30 \%$ for each question and in this instance; consensus was achieved after first iteration. The Delphi consensus suggested median effect of $20 \%$ reduction in antepartum and intrapartum stillbirths with the HDP package with interquartile ranges of $10-30 \%$ and $10-40 \%$ respectively (Figure 6).

\section{Discussion}

Over 2.5 million babies are born dead each year, making stillbirth one of the most important adverse outcomes of pregnancy [88]. Hypertension during pregnancy is a risk factor for stillbirth [89-91] especially in low socioeconomic settings [92]. The two most commonly used preventive measures are; use of aspirin in high risk pregnancies and calcium supplementation in populations with low calcium intake [20]. In this review we have 


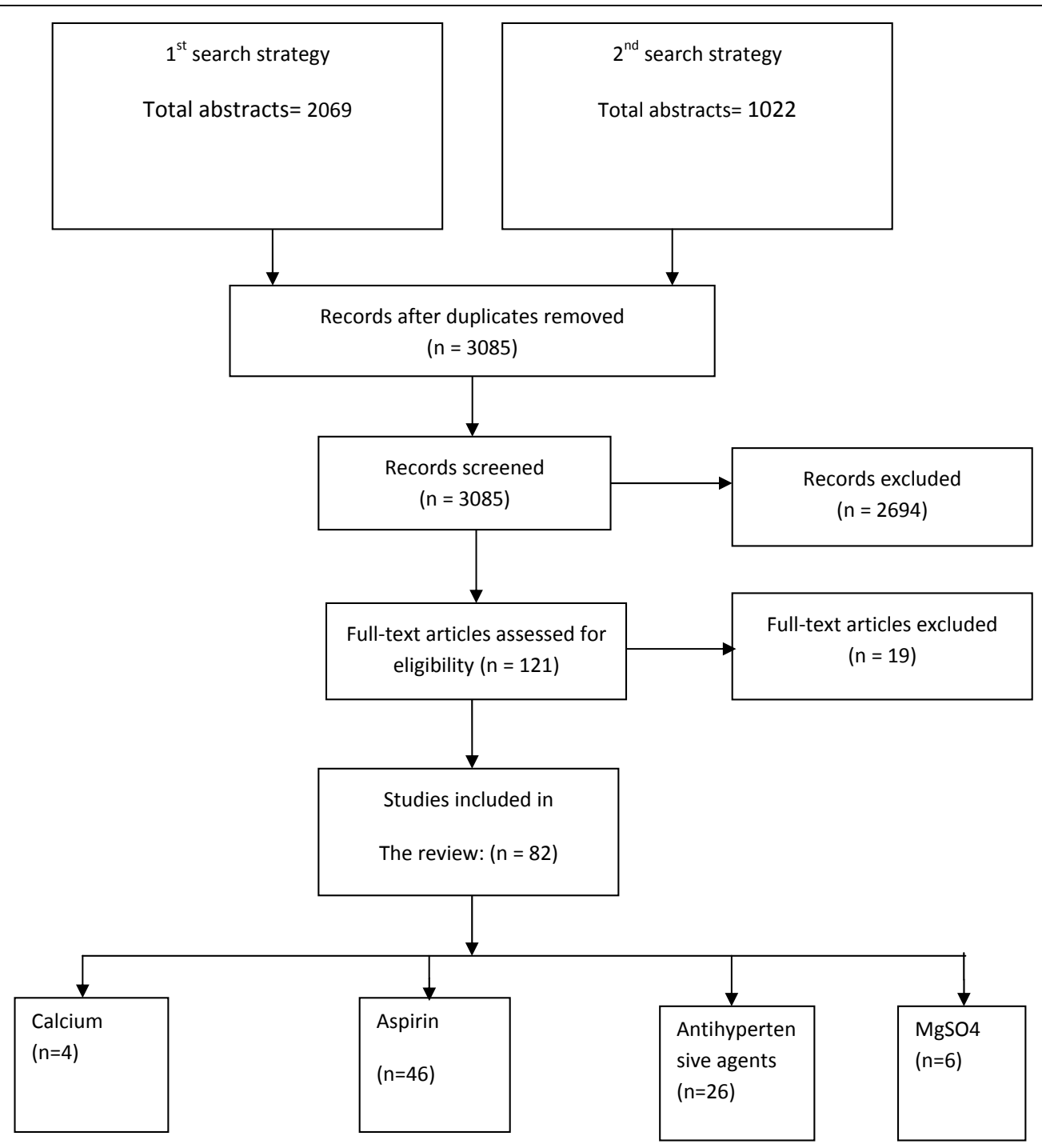

Figure 1 Flow chart for study selection.

Table 1 Quality assessment of trials of aspirin alone in high-risk pregnancies for prevention of preeclampsia

\begin{tabular}{|c|c|c|c|c|c|c|c|c|}
\hline \multicolumn{4}{|c|}{ Quality Assessment } & \multirow{2}{*}{\multicolumn{2}{|c|}{ Directness }} & \multicolumn{3}{|c|}{ Summary of Findings } \\
\hline & & & & & & No of events & & \\
\hline $\begin{array}{l}\text { No of } \\
\text { studies } \\
\text { (ref) }\end{array}$ & Design & Limitations & Consistency & $\begin{array}{l}\text { Generalizability } \\
\text { to population } \\
\text { of interest }\end{array}$ & $\begin{array}{l}\text { Generalizability } \\
\text { to intervention } \\
\text { of interest }\end{array}$ & Intervention & Control & $\begin{array}{l}\text { Relative Risk } \\
(95 \% \mathrm{Cl})\end{array}$ \\
\hline \multicolumn{9}{|c|}{ Stillbirths: LOW outcome specific quality } \\
\hline 21 & $\mathrm{RCT}$ & $\begin{array}{l}\text { High non-compliance } \\
\text { rate, Small sample size, } \\
\text { Placebo not used, Not } \\
\text { double-blinded. }\end{array}$ & $\begin{array}{l}\text { Consistent; Low } \\
\text { heterogeneity } \\
(p=0.62) ; \text { Results } \\
\text { statistically } \\
\text { insignificant }\end{array}$ & $\begin{array}{l}1 \text { study in } \\
\text { developing } \\
\text { country }\end{array}$ & Yes & 113 & 95 & $1.15(0.88,1.49)$ \\
\hline \multicolumn{9}{|c|}{ Perinatal mortality: MODERATE/LOW outcome specific quality } \\
\hline 13 & $\mathrm{RCT}$ & $\begin{array}{l}\text { Low compliance; Small } \\
\text { sample size }\end{array}$ & $\begin{array}{l}\text { Consistent; Low } \\
\text { heterogeneity } \\
(p=0.39) ; \text { Results } \\
\text { statistically } \\
\text { insignificant }\end{array}$ & $\begin{array}{l}3 \text { studies in } \\
\text { developing } \\
\text { countries }\end{array}$ & Yes & 187 & 209 & $0.89(0.74,1.08)$ \\
\hline
\end{tabular}


Table 2 Quality assessment of studies of calcium supplementation during pregnancy to prevent stillbirths from maternal hypertensive disorders:

\begin{tabular}{|c|c|c|c|c|c|c|c|c|}
\hline \multicolumn{4}{|c|}{ Quality Assessment } & \multicolumn{2}{|l|}{ Directness } & \multicolumn{3}{|c|}{ Summary of findings } \\
\hline $\begin{array}{l}\text { No. of } \\
\text { studies } \\
\text { (Ref) }\end{array}$ & Design & Limitations & Consistency & $\begin{array}{l}\text { Generalizability } \\
\text { to Population of } \\
\text { Interest }\end{array}$ & $\begin{array}{l}\text { Generalizability to intervention } \\
\text { of Interest }\end{array}$ & $\begin{array}{l}\text { Events in } \\
\text { intervention } \\
\text { group }\end{array}$ & $\begin{array}{l}\text { Events in } \\
\text { control } \\
\text { group }\end{array}$ & $\begin{array}{l}\text { Relative Risk } \\
(95 \% \mathrm{Cl})\end{array}$ \\
\hline \multicolumn{9}{|c|}{ Stillbirth: Moderate outcome specific quality } \\
\hline 3 & $\mathrm{RCT}$ & None & $\begin{array}{l}\text { Consistent } \\
\left(1^{2}=0\right)\end{array}$ & $\begin{array}{l}\text { Yes all from } \\
\text { developing } \\
\text { countries }\end{array}$ & $\begin{array}{l}\text { Dose of calcium supplementation } \\
\text { ranged from } 1.5-2 \mathrm{~g} / \text { day in all the } \\
\text { included studies }\end{array}$ & 117 & 145 & $0.81(0.63-1.03) a$ \\
\hline \multicolumn{9}{|c|}{ Perinatal mortality: Low outcome specific quality } \\
\hline 4 & RCTs & None & $\begin{array}{l}\text { Consistent } \\
\left(1^{2}=0\right)\end{array}$ & $\begin{array}{l}\text { Yes All from } \\
\text { developing } \\
\text { countries }\end{array}$ & $\begin{array}{l}\text { Dose of calcium supplementation } \\
\text { ranged from } 1.5-2 \mathrm{~g} / \text { day in all the } \\
\text { included studies }\end{array}$ & 154 & 179 & $0.86(0.70-1.07) a$ \\
\hline
\end{tabular}

found that use of aspirin was not associated with a decrease in stillbirths ( $R R=1.15 ; 95 \% \mathrm{CI}: 0.88$ to 1.49$)$. Results of this review are different from that of Cochrane review [25] on the topic (aspirin) as data for stillbirth were pooled with miscarriages in the Cochrane review. The combined results in the Cochrane review also showed no effect of aspirin $(\mathrm{RR}=0.96 ; \mathrm{CI}=0.78$ to 1.18]. In any case, despite having a protective effect against pre-eclampsia, there was no convincing evidence to recommend use of 'aspirin alone' for reduction of stillbirths for input to the Live Saved Tool (LiST).

Analysis in this review has shown that calcium supplementation during pregnancy reduced stillbirths by $19 \%$; however results were not statistically significant (RR 0.81, 95 \% CI 0.63-1.03). A Cochrane review on effectiveness of calcium supplementation during pregnancy [24] also showed a statistically insignificant 30\% reduction in the outcome of stillbirths or death before discharge (RR $0.70,95 \%$ CI 0.69 to 1.09 ). There was however $55 \%$ reduction in risk of preeclampsia (RR $0.45,95 \%$ CI 0.31 to 0.65 ). Although the evidence in support of calcium supplementation for women at risk of low intake is robust [24], further research is needed with assessment of the full range of pregnancy outcomes before this can be recommended for inclusion in the LiST model for prevention of stillbirth.

This review has shown that use of antihypertensive drugs has no effect on incidence of stillbirths, which is similar to the results from the Cochrane review $(\mathrm{RR}=1.14 \mathrm{CI}=0.60$ to 2.17$)$ [3].

It should be noted that most data included in this review for aspirin, antihypertensive agents and magnesium sulphate was from developed countries, as data from developing countries was scarce. Several studies had too small a sample size to be able to detect differences in stillbirths. Moreover, noncompliance rates to the aspirin were as high as $20 \%$ in certain studies. In a few studies, a no-treatment group was used as a control group instead of a placebo group, which may have affected the results.

Given these limitations of the data, we also used the Delphi process to generate an impact estimate for impact of a package of interventions that involve detection and management of hypertensive disease of pregnancy. The package included use of an appropriate antihypertensive, magnesium supplementation in case of

Table 3 Quality assessment of trials of antihypertensive agents in pregnancies with mild to moderate hypertension

\begin{tabular}{|c|c|c|c|c|c|c|c|c|}
\hline \multirow[b]{3}{*}{$\begin{array}{l}\text { No of } \\
\text { studies } \\
\text { (ref) }\end{array}$} & \multicolumn{5}{|c|}{ Quality Assessment } & \multicolumn{3}{|c|}{ Summary of Findings } \\
\hline & \multirow[b]{2}{*}{ Design } & \multirow[b]{2}{*}{ Limitations } & \multirow[b]{2}{*}{ Consistency } & \multicolumn{2}{|l|}{ Directness } & \multicolumn{2}{|l|}{ No of events } & \multirow[b]{2}{*}{$\begin{array}{l}\text { Relative Risk } \\
(95 \% \mathrm{CI})\end{array}$} \\
\hline & & & & $\begin{array}{l}\text { Generalizability } \\
\text { to population of } \\
\text { interest }\end{array}$ & $\begin{array}{l}\text { Generalizability } \\
\text { to intervention } \\
\text { of interest }\end{array}$ & Intervention & Control & \\
\hline \multicolumn{9}{|c|}{ Stillbirths: MODERATE/LOW outcome specific quality } \\
\hline 18 & $\mathrm{RCT}$ & $\begin{array}{l}\text { Small sample } \\
\text { size, Placebo } \\
\text { not used }\end{array}$ & $\begin{array}{l}\text { Consistent; Low } \\
\text { heterogeneity }(\mathrm{p}=0.93) \text {; } \\
\text { Results statistically } \\
\text { insignificant }\end{array}$ & $\begin{array}{l}3 \text { studies in } \\
\text { developing } \\
\text { countries }\end{array}$ & Yes & 18 & 16 & $1.14(0.60,2.17)$ \\
\hline \multicolumn{9}{|c|}{ Perinatal mortality: MODERATE/LOW outcome specific quality } \\
\hline 20 & $\mathrm{RCT}$ & $\begin{array}{l}\text { Small sample } \\
\text { size, Placebo } \\
\text { not used }\end{array}$ & $\begin{array}{l}\text { Consistent; Low } \\
\text { heterogeneity ( } p=0.97) \text {; } \\
\text { Results statistically } \\
\text { insignificant }\end{array}$ & $\begin{array}{l}3 \text { studies in } \\
\text { developing } \\
\text { countries }\end{array}$ & Yes & 30 & 82 & $0.96(0.60,1.54)$ \\
\hline
\end{tabular}


Table 4 Quality assessment of trials of magnesium sulphate in pregnancies with preeclampsia

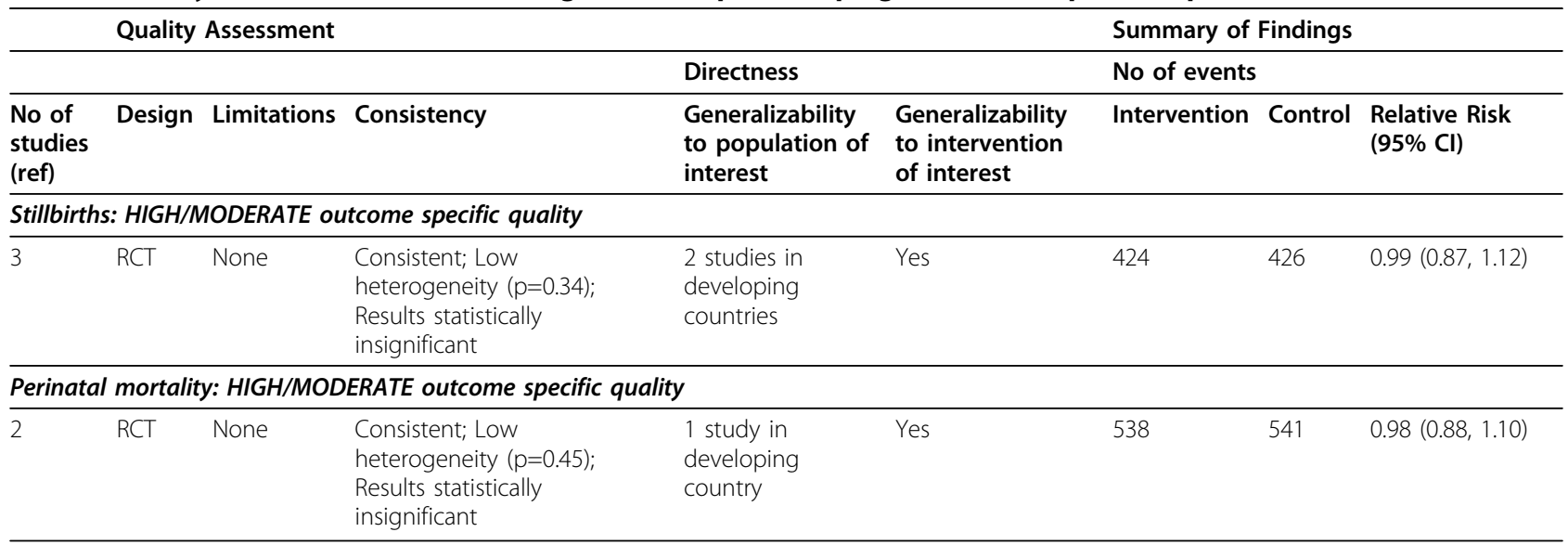

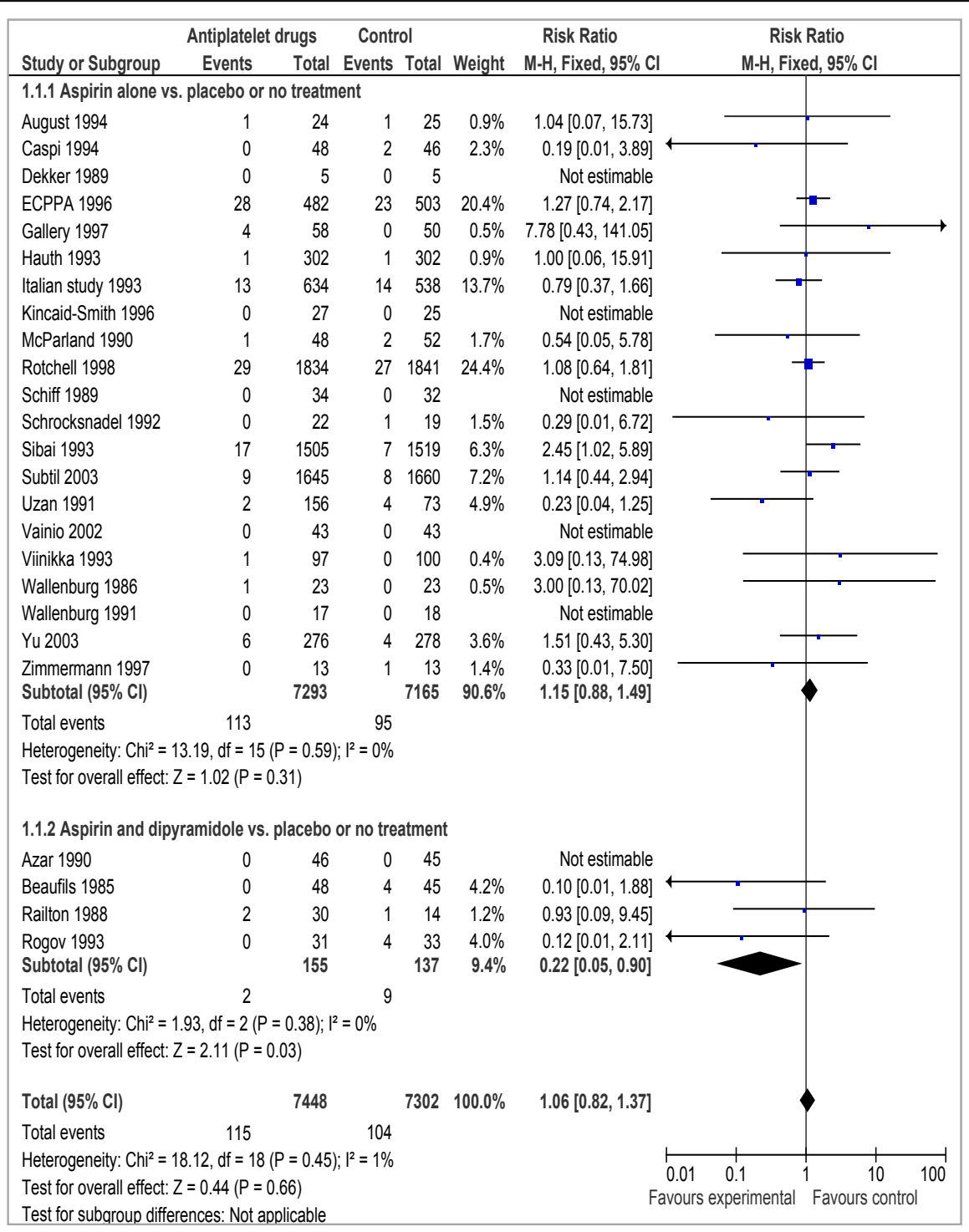

Figure 2 Forest plot for the effect of aspirin on stillbirths. 


\begin{tabular}{|c|c|c|c|c|c|c|c|}
\hline \multirow[b]{2}{*}{ Stucty or Subgroup } & \multicolumn{2}{|c|}{ Calcium } & \multicolumn{2}{|c|}{ Placebo } & \multirow[b]{2}{*}{ Weight } & \multirow{2}{*}{$\begin{array}{c}\text { Risk Ratio } \\
\text { M-H, Fixed, 95\% Cl }\end{array}$} & \multirow{2}{*}{$\begin{array}{c}\text { Risk Ratio } \\
\text { M-H, Fixed, 95\% Cl } \\
\end{array}$} \\
\hline & Events & Total & Events & Total & & & \\
\hline Belizan 1991 & 6 & 558 & 7 & 567 & $4.8 \%$ & $0.87[0.29,2.58]$ & | \\
\hline Kumar 2009 & 6 & 273 & 5 & 251 & $3.6 \%$ & $1.10[0.34,3.57]$ & \\
\hline Villar 2006 & 105 & 4181 & 133 & 4197 & $91.6 \%$ & $0.79[0.62,1.02]$ & \\
\hline Total (95\% Cl) & & 5012 & & 5015 & $100.0 \%$ & $0.81[0.63,1.03]$ & \\
\hline Total events & 117 & & 145 & & & & \\
\hline $\begin{array}{l}\text { Heterogeneity: } \mathrm{Chi}^{2}= \\
\text { Test for overall effect }\end{array}$ & $\begin{array}{l}0.31, \mathrm{df}= \\
Z=1.74\end{array}$ & $\begin{array}{l}2(P= \\
P=0.0\end{array}$ & $0.86) ; 1^{2}=$ & $=0 \%$ & & & $\begin{array}{cccc}0.01 & 0.1 & 1 & 10 \\
\text { Favours experimental } & \text { Favours control }\end{array}$ \\
\hline
\end{tabular}

Figure 3 Forest plot for the effect of calcium supplementation on stillbirths.

preeclampsia/eclampsia and availability of C-section when required. The selection of this package was based on the fact these interventions are accepted standards of care for management of preeclampsia/eclampsia [6]; however their role in prevention of stillbirths has not been extensively studied as described above. We therefore contacted experts in the field (total 33) and asked their opinion on how effective this package of intervention could be to reduce incidence of stillbirths. The results yielded a reduction of $20 \%$ in antepartum and intrapartum stillbirths. It should be noted that this evidence is based on expert's opinion only and considered as the weakest evidence in the CHERG's methods of evaluation of effectiveness of an intervention [23]. We therefore recommend that future research should focus on better understanding of the role of detection and

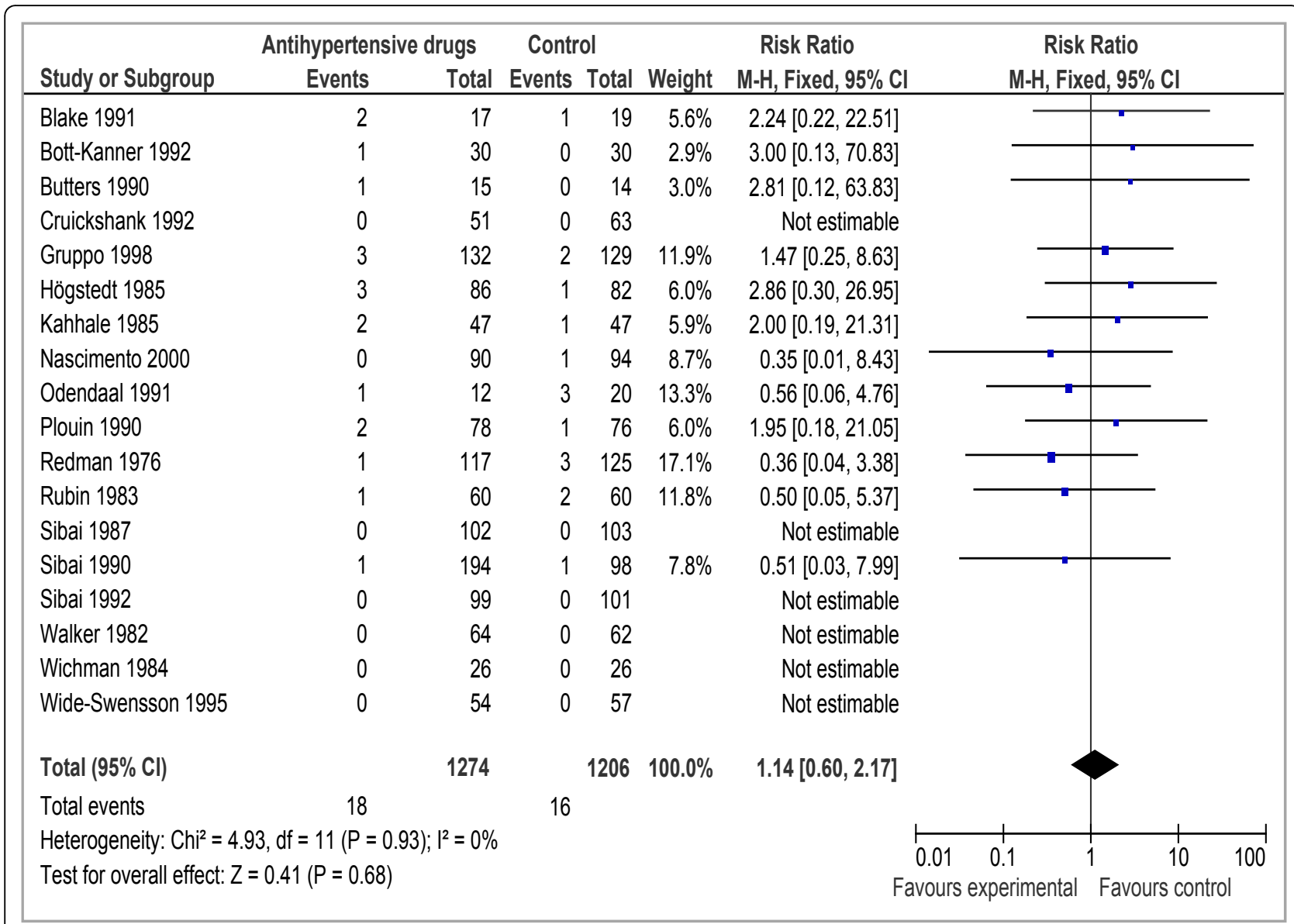

Figure 4 Forest plot for the effect of antihypertensive agents on stillbirths. 


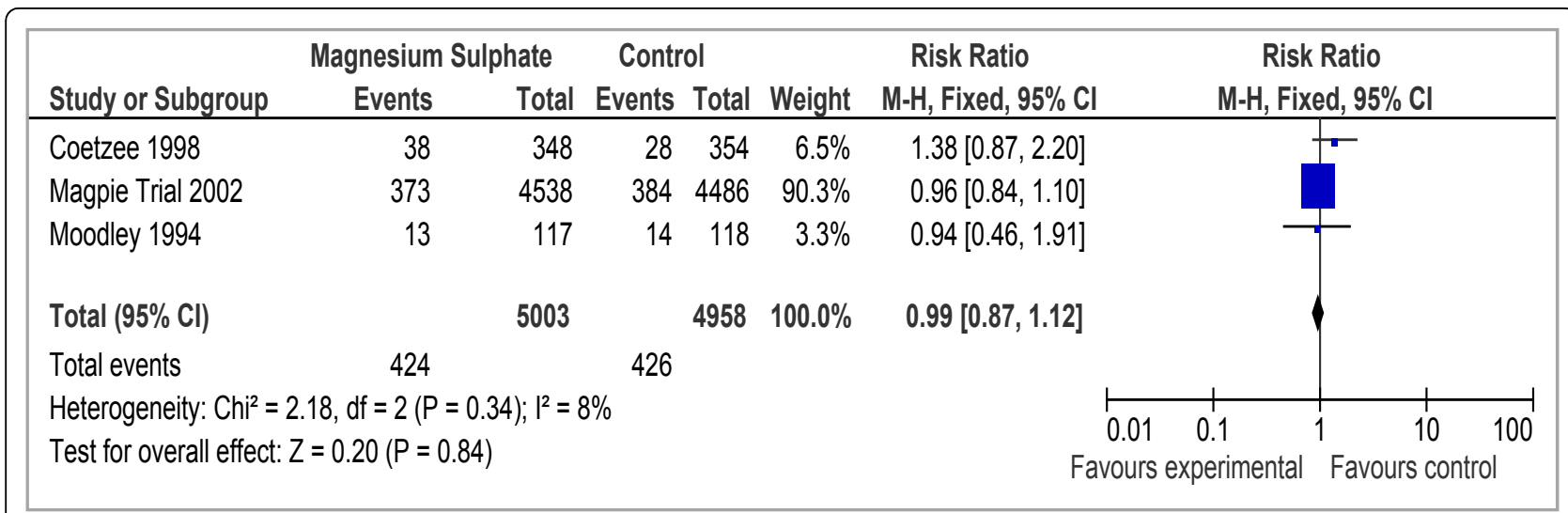

Figure 5 Forest plot for the effect of magnesium sulphate on stillbirths.

management of gestational hypertensive disorders in prevention of stillbirths. It is possible that a package of interventions has an effect that is greater than the individual components and the inclusion of, for example, $\mathrm{C}$ Section, may explain the effect attributed to the package as a whole by the experts. Finally, it is possible the experts were unaware of negative summary data of components of the package.

\section{Conclusion}

In conclusion, aspirin and calcium play a significant role in prevention of preeclampsia however their role in reducing stillbirths is not well established. Antihypertensive and magnesium sulphate supplementation for hypertensive disorders in pregnancy reduce morbidity and mortality associated with these disorders however their role in reducing stillbirths is not clear. Based on expert's opinion a package of detection and management of gestational hypertensive disorders (Antihypertensive, $\mathrm{MgSO} 4$ and C-

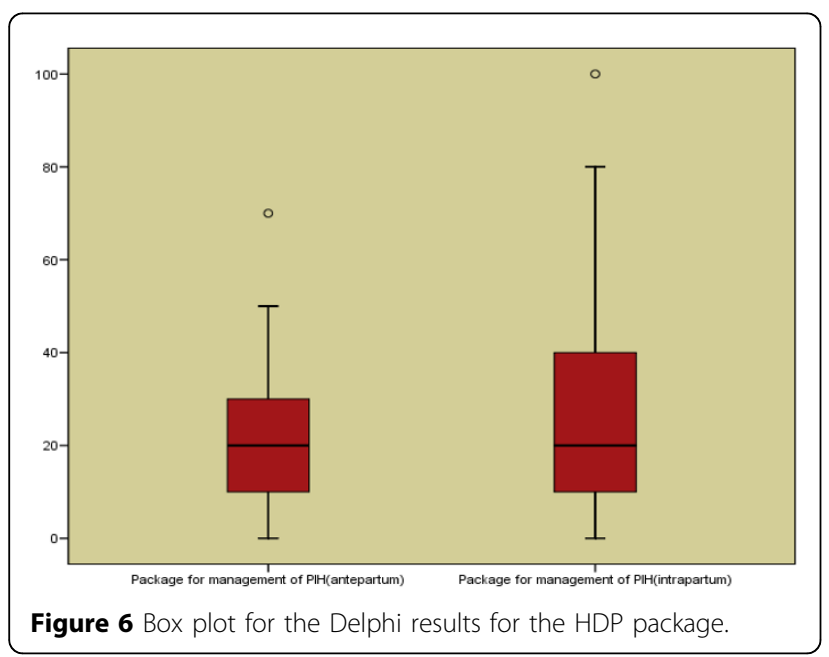

Section) was estimated to reduce the incidence of stillbirths by $20 \%$.

\section{Additional material}

Additional File 1: Data extraction sheet for studies included in the review.

\section{Acknowledgements}

This work was supported in part by a grant to the US Fund for UNICEF from the Bill \& Melinda Gates Foundation (grant 43386) to "Promote evidencebased decision making in designing maternal, neonatal and child health interventions in low- and middle-income countries".

This article has been published as part of BMC Public Health Volume 11

Supplement 3, 2011: Technical inputs, enhancements and applications of the Lives Saved Tool (LiST). The full contents of the supplement are available online at http://www.biomedcentral.com/1471-2458/11?issue=S3.

\section{Authors' contributions}

Professor Zulfiqar A Bhutta developed the review parameters and secured support. Drs Mehnaz Jabeen, Yawar Yakoob and Aamer Imdad undertook the literature search, data extraction and analysis under the supervision of Professor Bhutta. Professor Bhutta gave advice in all the aspects of the project and was the overall supervisor.

\section{Competing interests}

The authors declare no conflict of interest

Published: 13 April 2011

\section{References}

1. $Y u$ CKH, P AT, parra M, Palma Das R, Nicolaides KH: Randomized controlled trial using low-dose aspirin in the prevention of pre-eclampsia in women with abnormal uterine Doppler at 23 weeks gestation. Ultrasound in Obstetrics \& Gynecology 2003, 22:233-239.

2. Khan KS, Wojdyla D, Say L, Gulmezoglu AM, Van Look PF: WHO analysis of causes of maternal death: a systematic review. Lancet 2006, 367(9516):1066-1074.

3. Abalos E, Duley L, Steyn DW, Henderson-Smart DJ: Antihypertensive drug therapy for mild to moderate hypertension during pregnancy. Cochrane Database Syst Rev 2007, , 1: CD002252.

4. Italian Study of Aspirin in Pregnancy: Low-dose aspirin in prevention and treatment of intrauterine growth retardation and pregnancy-induced hypertension. Lancet 1993, 341(8842):396-400. 
5. Ananth CV, Basso O: Impact of pregnancy-induced hypertension on stillbirth and neonatal mortality. Epidemiology 2010, 21(1):118-123.

6. Norwitz ER, Repke JT: Preeclampsia prevention and management. J SoC Gynecol Investig 2000, 7(1):21-36.

7. Ronsmans C, Campbell O: Quantifying the fall in mortality associated with interventions related to hypertensive diseases of pregnancy. BMC Public Health

8. Hofmeyr GJ, Lawrie TA, Atallah AN, Duley L: Calcium supplementation during pregnancy for preventing hypertensive disorders and related problems. Cochrane Database Syst Rev 2010, , 8: CD001059.

9. Vainio M, Kujansuu E, Iso-Mustajarvi M, Maenpaa J: Low dose acetylsalicylic acid in prevention of pregnancy-induced hypertension and intrauterine growth retardation in women with bilateral uterine artery notches. BJOG 2002, 109(2):161-167.

10. Wide-Swensson DH, Ingemarsson I, Lunell NO, Forman A, Skajaa K, Lindberg B, Lindeberg S, Marsal K, Andersson KE: Calcium channel blockade (isradipine) in treatment of hypertension in pregnancy: a randomized placebo-controlled study. Am J Obstet Gynecol 1995, 173(3 Pt 1):872-878.

11. Tulppala M, Marttunen M, Soderstrom-Anttila V, Foudila T, Ailus K, Palosuo T, Ylikorkala O: Low-dose aspirin in prevention of miscarriage in women with unexplained or autoimmune related recurrent miscarriage: effect on prostacyclin and thromboxane A2 production. Hum Reprod 1997, 12(7):1567-1572.

12. Uzan S, Beaufils M, Breart G, Bazin B, Capitant C, Paris J: Prevention of fetal growth retardation with low-dose aspirin: findings of the EPREDA trial. Lancet 1991, 337(8755):1427-1431.

13. Schiff E, Peleg E, Goldenberg M, Rosenthal T, Ruppin E, Tamarkin M, Barkai G, Ben-Baruch G, Yahal I, Blankstein J, et al: The use of aspirin to prevent pregnancy-induced hypertension and lower the ratio of thromboxane A2 to prostacyclin in relatively high risk pregnancies. $N$ Engl J Med 1989, 321(6):351-356.

14. Sibai BM, Mabie WC, Shamsa F, Villar MA, Anderson GD: A comparison of no medication versus methyldopa or labetalol in chronic hypertension during pregnancy. Am J Obstet Gynecol 1990, 162(4):960-966, discussion 966-967.

15. Sibai BM, Caritis SN, Thom E, Klebanoff M, McNellis D, Rocco L, Paul RH, Romero R, Witter F, Rosen M, et al: Prevention of preeclampsia with lowdose aspirin in healthy, nulliparous pregnant women. The National Institute of Child Health and Human Development Network of MaternalFetal Medicine Units. N Engl J Med 1993, 329(17):1213-1218.

16. Wallenburg HC, Dekker GA, Makovitz JW, Rotmans N: Effect of low-dose aspirin on vascular refractoriness in angiotensin-sensitive primigravid women. Am J Obstet Gynecol 1991, 164(5 Pt 1):1169-1173.

17. Subtil D, Goeusse P, Puech F, Lequien P, Biausque S, Breart G, Uzan S, Marquis $P$, Parmentier $D$, Churlet A: Aspirin (100 mg) used for prevention of pre-eclampsia in nulliparous women: the Essai Regional Aspirine Mere-Enfant study (Part 1). BJOG 2003, 110(5):475-484

18. Viinikka L, Hartikainen-Sorri AL, Lumme R, Hiilesmaa V, Ylikorkala O: Low dose aspirin in hypertensive pregnant women: effect on pregnancy outcome and prostacyclin-thromboxane balance in mother and newborn. Br J Obstet Gynaecol 1993, 100(9):809-815.

19. Wallenburg HC, Dekker GA, Makovitz JW, Rotmans P: Low-dose aspirin prevents pregnancy-induced hypertension and pre-eclampsia in angiotensin-sensitive primigravidae. Lancet 1986, 1(8471):1-3.

20. Bhutta ZA, Ali S, Cousens S, Ali TM, Haider BA, Rizvi A, Okong P, Bhutta SZ, Black RE: Alma-Ata: Rebirth and Revision 6 Interventions to address maternal, newborn, and child survival: what difference can integrated primary health care strategies make? Lancet 2008, 372(9642):972-989.

21. Duley L, Gulmezoglu AM, Henderson-Smart DJ, Chou D: Magnesium sulphate and other anticonvulsants for women with pre-eclampsia. Cochrane Database Syst Rev 2010, 11:CD000025.

22. Atkins D, Best D, Briss PA, Eccles M, Falck-Ytter $Y$, Flottorp S, Guyatt GH, Harbour RT, Haugh MC, Henry D, et al: Grading quality of evidence and strength of recommendations. BMJ 2004, 328(7454):1490.

23. Walker N, Fischer-Walker C, Bryce J, Bahl R, Cousens S: Standards for CHERG reviews of intervention effects on child survival. Int J Epidemiol 2010, 39(Suppl 1):i21-31.

24. Hofmeyr GJ, Atallah AN, Duley L: Calcium supplementation during pregnancy for preventing hypertensive disorders and related problems. Cochrane Database Syst Rev 2006, 3:CD001059.
25. Duley L, Henderson-Smart DJ, Meher S, King JF: Antiplatelet agents for preventing pre-eclampsia and its complications. Cochrane Database Syst Rev 2007, 2: CD004659.

26. Duley L, Gulmezoglu AM, Henderson-Smart DJ: Magnesium sulphate and other anticonvulsants for women with pre-eclampsia. Cochrane Database Syst Rev 2003, , 2: CD000025.

27. Kincaid-Smith P: Trial to evaluate the role of aspirin $(60 \mathrm{mg})$ in the prevention of idiopathic intrauterine growth retardation and pregnancy induced hypertension in primigravid women with abnormal uterine artery waveforms on Doppler examination at 22-24 weeks gestation. Personal communication 1996.

28. Gallery EDM, R M, Hawkins M, Leslie Gl, Gyory AZ: Low-dose aspirin in high-risk pregnancy. 1997, 16:229-238.

29. Schrocksnadel H, Sitte B, Alge A, Steckel-Berger G, Schwegel P, Pastner E, Daxenbichler G, Hansen H, Dapunt O: Low-dose aspirin in primigravidae with positive roll-over test. Gynecol Obstet Invest 1992, 34(3):146-150.

30. Rotchell YE, Cruickshank JK, Gay MP, Griffiths J, Stewart A, Farrell B, Ayers S, Hennis A, Grant A, Duley L, et al: Barbados Low Dose Aspirin Study in Pregnancy (BLASP): a randomised trial for the prevention of pre-eclampsia and its complications. Br J Obstet Gynaecol 1998, 105(3):286-292.

31. ECPPA (Estudo Colaborativo para Prevencao da Pre-eclampsia com Aspirina) Collaborative Group: ECPPA: randomised trial of low dose aspirin for the prevention of maternal and fetal complications in high risk pregnant women. Br J Obstet Gynaecol 1996, 103(1):39-47.

32. Zimmermann P, E V, Koskinen J, Niemi K, Nyman R, Kujansuu E: Effect of low dose aspirin treatment on vascular resistance in the uterine, uteroplacental, renal and umbilical arteries - a prospective longitudinal study on a high risk population with persistent notch in the uterine arteries. European Journal of Ultrasound 1997, 5:17-30.

33. Caspi E, Raziel A, Sherman D, Arieli S, Bukovski I, Weinraub Z: Prevention of pregnancy-induced hypertension in twins by early administration of low-dose aspirin: a preliminary report. Am J Reprod Immunol 1994, 31(1):19-24.

34. Dekker GA: Prediction and prevention of pregnancy-induced hypertensive disorders: a clinical and pathophysiologic study [MD thesis]. 1989.

35. MCParland P, Pearce JM, Chamberlain GV: Doppler ultrasound and aspirin in recognition and prevention of pregnancy-induced hypertension. Lancet 1990, 335(8705):1552-1555.

36. Hauth JC, Goldenberg RL, Parker CR Jr., Philips JB 3rd, Copper RL, DuBard MB, Cutter GR: Low-dose aspirin therapy to prevent preeclampsia. Am J Obstet Gynecol 1993, 168(4):1083-1091, discussion 1091-1083.

37. August $P, H$ G, Edersheim TG, Hutson JM, Druzin M: Sustained release, low-dose aspirin ameliorates but does not prevent preeclampsia (PE) in a high risk population. Proceedings of 9th International Congress, International Society for the Study of Hypertension in Pregnancy Sydney, Australia; 1994, 72

38. Beaufils M, Uzan S, Donsimoni R, Colau JC: Prevention of pre-eclampsia by early antiplatelet therapy. Lancet 1985, 1(8433):840-842.

39. Rogov $V, T$ I, Sidorova $S$, Androsova S: Prevention of pregnancy complications with acetylsalicylic acid (ASA) and dipyridamol (DP) in women with chronic glomerulonephritis (CGN) and essential hypertension (EH). Proceedings of 9th International Congress of the International Society for the Study of Hypertension in Pregnancy Sydney, Australia; 1994, 280.

40. Railton A, D A: Aspirin and dipyridamole in the prevention of preeclampsia: effect on plasma prostanoids 6 keto PG1a and TXB2 and clinical outcome of pregnancy. Proceedings of the 6th International Congress of the International Society for the Study of Hypertension in Pregnancy Montreal, Quebec, Canada; 1988.

41. Byaruhanga RN, C T, Rusakaniko S: A randomized controlled trial of lowdose aspirin in women at risk from pre-eclampsia. International Journal of Gynecology \& Obstetrics 1998, 60:129-135.

42. Davies NJ, G M, Farquharson RG, Walkinshaw SA: Low-dose aspirin in the prevention of hypertensive disorders of pregnancy in relatively low-risk nulliparous women. Hypertension in Pregnancy 1995, 14:49-55.

43. Golding J: A randomised trial of low dose aspirin for primiparae in pregnancy. The Jamaica Low Dose Aspirin Study Group. Br J Obstet Gynaecol 1998, 105(3):293-299. 
44. CLASP (Collaborative Low-dose Aspirin Study in Pregnancy) Collaborative Group: CLASP: a randomised trial of low-dose aspirin for the prevention and treatment of pre-eclampsia among 9364 pregnant women. Lancet 1994, 343(8898):619-629.

45. Michael CA, W B: Low-dose aspirin in the prevention of pre-eclampsia: current evaluation. In Maternal physiology and pathology Low-dose aspirin in the prevention of pre-eclampsia: current evaluation Teoh ES, Ratnam SS, Macnaughton MC 1993, 183.

46. Morris JM, Fay RA, Ellwood DA, Cook CM, Devonald KJ: A randomized controlled trial of aspirin in patients with abnormal uterine artery blood flow. Obstet Gynecol 1996, 87(1):74-78.

47. Rogers MS, Fung HY, Hung CY: Calcium and low-dose aspirin prophylaxis in women at high risk of pregnancy-induced hypertension. Hypertens Pregnancy 1999, 18(2):165-172.

48. Wang Z, Li W: A prospective randomized placebo-controlled trial of lowdose aspirin for prevention of intra-uterine growth retardation. Chin Med $J($ Engl) 1996, 109(3):238-242.

49. Ebrashy A, I M, Marzook A, Yousef D: Usefulness of aspirin therapy in high-risk pregnant women with abnormal uterine artery doppler ultrasound at 14-16 weeks pregnancy: randomized controlled clinical trial. Croatian Medical Journal 2005, 46:826.

50. Volpicelli T, D'Anto V, Faticato A, Galante L, Civitillo RM, Rappa C: Gestosi '99. 1999, 159.

51. Hermida RC, A D, Iglesias M, Mojon A, Silva I, Ucieda R: Time-dependant effects of low dose aspirin administration on blood pressure in pregnant women. Hypertension 1997, 30:589.

52. Ramaiya C, Mgaya HN: Low dose aspirin in prevention of pregnancyinduced hypertension in primigravidae at the Muhimbili Medical Center, Dar es Salaam. East Afr Med J 1995, 72(11):690-693.

53. Caritis S, Sibai B, Hauth J, Lindheimer MD, Klebanoff M, Thom E, VanDorsten P, Landon M, Paul R, Miodovnik M, et al: Low-dose aspirin to prevent preeclampsia in women at high risk. National Institute of Child Health and Human Development Network of Maternal-Fetal Medicine Units. N Engl J Med 1998, 338(11):701-705.

54. Rivas-Echeverria CA, E Y, Molina L, Novoa D: Synergic use of aspirin, fish oil and vitamins $C$ and $E$ for the prevention of preeclampsia. 2000, 19:30.

55. JM B: Prevention of hypertensive disorders of pregnancy with calcium supplementation. 8th World Congress on Hypertension in Pregnancy; 1992 November 8-12; Buenos Aires; 1991.

56. Kumar A, Devi SG, Batra S, Singh C, Shukla DK: Calcium supplementation for the prevention of pre-eclampsia. Int J Gynaecol Obstet 2009, 104(1):32-36.

57. Villar J, A AH, Merialdi M, Mathai M, Ali M, Zavaleta N, et al: World Health Organisation randomized trial of calcium supplementation among low calcium intake pregnant women. American Journal of Obstetrics and Gynecology 2006, 194:639.

58. Kahhale S, Z M, Carrara W, Paula FJ, Sabbaga E, Neme B: Comparative study of chronic hypertensive pregnant women treated and non-treated with pindolol. Ginecologia e ObstetrÃcia Brasileiras 1985, 8:85.

59. DJ N: Evaluation of the use of Verapamil with non-serious form of chronic vascular hypertension disease during pregnancy Doctoral thesis. 2000.

60. Plouin PF, Breart G, Llado J, Dalle M, Keller ME, Goujon H, Berchel C: A randomized comparison of early with conservative use of antihypertensive drugs in the management of pregnancy-induced hypertension. Br J Obstet Gynaecol 1990, 97(2):134-141.

61. Blake S, MacDonald D: The prevention of the maternal manifestations of pre-eclampsia by intensive antihypertensive treatment. $\mathrm{Br} J$ Obstet Gynaecol 1991, 98(3):244-248.

62. Bott-Kanner G, H M, Friedman S, Boner G, Ovadia J, Merlob P, et al: Antihypertensive therapy in the management of hypertension in pregnancy - a clinical double-blind study of pindolol. Clinical and Experimental Hypertension 1992, B11:207.

63. Gruppo di Studio Ipertensione in Gravidanza: Nifedipine versus expectant management in mild to moderate hypertension in pregnancy. Gruppo di Studio Ipertensione in Gravidanza. Br J Obstet Gynaecol 1998, 105(7):718-722.

64. Odendaal HJ, S I, Pattinson RC: Prazosin for the treatment of hypertension in pregnancy: a randomized control trial. In Oxford Database of Perinatal Trials, Version 12. Oxford: Oxford University Press;Autumn Chalmers I 1991: Disk Issue 6.
65. Wichman K, Ryden G, Karlberg BE: A placebo controlled trial of metoprolol in the treatment of hypertension in pregnancy. Scand J Clin Lab Invest Supp/ 1984, 169:90-95.

66. Hogstedt S, Lindeberg S, Axelsson O, Lindmark G, Rane A, Sandstrom B, Lindberg BS: A prospective controlled trial of metoprolol-hydralazine treatment in hypertension during pregnancy. Acta Obstet Gynecol Scand 1985, 64(6):505-510.

67. Redman CW: Fetal outcome in trial of antihypertensive treatment in pregnancy. Lancet 1976, 2(7989):753-756.

68. Walker JJ, C A, Erwin L, Calder AA: Labetalol in pregnancy-induced hypertension: fetal and maternal effects. In International Congress Series 591 Amsterdam: Excerpta Medica Reilly A, Symonds EM 1982, 148.

69. Rubin PC, Butters L, Clark DM, Reynolds B, Sumner DJ, Steedman D, Low RA, Reid JL: Placebo-controlled trial of atenolol in treatment of pregnancy-associated hypertension. Lancet 1983, 1(8322):431-434.

70. Butters L, Kennedy S, Rubin PC: Atenolol in essential hypertension during pregnancy. BMJ 1990, 301(6752):587-589.

71. Cruickshank DJ, R A, Campbell DM, MacGillivray I: Maternal obstetric outcome measures in a randomised controlled study of labetalol in the treatment of hypertension in pregnancy. Clinical and Experimental Hypertension 1991, B10:333.

72. Sibai BM, Gonzalez AR, Mabie WC, Moretti M: A comparison of labetalol plus hospitalization versus hospitalization alone in the management of preeclampsia remote from term. Obstet Gynecol 1987, 70(3 Pt 1):323-327.

73. Sibai BM, Barton JR, AkI S, Sarinoglu C, Mercer BM: A randomized prospective comparison of nifedipine and bed rest versus bed rest alone in the management of preeclampsia remote from term. Am J Obstet Gynecol 1992, 167(4 Pt 1):879-884.

74. Rosenfeld J, Bott-Kanner G, Boner G, Nissenkorn A, Friedman S, Ovadia J, Merlob P, Reisner S, Paran E, Zmora E, et al: Treatment of hypertension during pregnancy with hydralazine monotherapy or with combined therapy with hydralazine and pindolol. Eur J Obstet Gynecol Reprod Biol 1986, 22(4):197-204.

75. Paran E, Holzberg G, Mazor M, Zmora E, Insler V: Beta-adrenergic blocking agents in the treatment of pregnancy-induced hypertension. Int J Clin Pharmacol Ther 1995, 33(2):119-123.

76. Catalano D, E S, Pollio F, Ascione L, Russo C, De Santi B, et al: Evaluation of nifedipine monotherapy in the management of pregnancy hypertension. Giornale Italiano Di Ostetricia e Ginecologia 1997, 6:373.

77. Elhassan EM, Mirghani OA, Habour AB, Adam I: Methyldopa versus no drug treatment in the management of mild pre-eclampsia. East Afr Med J 2002, 79(4):172-175.

78. Leather HM, Humphreys DM, Baker P, Chadd MA: A controlled trial of hypotensive agents in hypertension in pregnancy. Lancet 1968, 2(7566):488-490

79. Pickles CJ, Broughton Pipkin F, Symonds EM: A randomised placebo controlled trial of labetalol in the treatment of mild to moderate pregnancy induced hypertension. Br J Obstet Gynaecol 1992, 99(12):964-968.

80. Weitz C, Khouzami V, Maxwell K, Johnson JW: Treatment of hypertension in pregnancy with methyldopa: a randomized double blind study. Int J Gynaecol Obstet 1987, 25(1):35-40.

81. Arias F, Zamora J: Antihypertensive treatment and pregnancy outcome in patients with mild chronic hypertension. Obstet Gynecol 1979, 53(4):489-494

82. Altman D, Carroli G, Duley L, Farrell B, Moodley J, Neilson J, Smith D: Do women with pre-eclampsia, and their babies, benefit from magnesium sulphate? The Magpie Trial: a randomised placebo-controlled trial. Lancet 2002, 359(9321):1877-1890.

83. Moodley J, M J: Prophylactic anticonvulsant therapy in hypertensive crises of pregnancy - the need for a large randomized trial. 1994, 13:245-252.

84. Coetzee EJ, Dommisse J, Anthony J: A randomised controlled trial of intravenous magnesium sulphate versus placebo in the management of women with severe pre-eclampsia. Br J Obstet Gynaecol 1998, 105(3):300-303.

85. Livingston JC, Livingston LW, Ramsey R, Mabie BC, Sibai BM: Magnesium sulfate in women with mild preeclampsia: a randomized controlled trial. Obstet Gynecol 2003, 101(2):217-220

86. Witlin AG, Friedman SA, Sibai BM: The effect of magnesium sulfate therapy on the duration of labor in women with mild preeclampsia at 
term: a randomized, double-blind, placebo-controlled trial. Am J Obstet Gynecol 1997, 176(3):623-627.

87. Chen FP, Chang SD, Chu KK: Expectant management in severe preeclampsia: does magnesium sulfate prevent the development of eclampsia? Acta Obstet Gynecol Scand 1995, 74(3):181-185.

88. Lawn JE, Yakoob MY, Haws RA, Soomro T, Darmstadt GL, Bhutta ZA: 3.2 million stillbirths: epidemiology and overview of the evidence review. BMC Pregnancy Childbirth 2009, 9(Suppl 1):S2.

89. Mbah AK, Alio AP, Marty PJ, Bruder K, Whiteman VE, Salihu HM: Preeclampsia in the first pregnancy and subsequent risk of stillbirth in black and white gravidas. Eur J Obstet Gynecol Reprod Biol 2010, 149(2):165-169.

90. Miller EC, Cao H, Wen SW, Yang Q, Lafleche J, Walker M: The risk of adverse pregnancy outcomes is increased in preeclamptic women who smoke compared with nonpreeclamptic women who do not smoke. Am J Obstet Gynecol 2010, 203(4):334 e331-338.

91. Onyiriuka AN: Analysis of stillbirths in a Nigerian mission hospital. Nig Q $J$ Hosp Med 2009, 19(1):27-31.

92. Hossain $\mathrm{N}$, Khan $\mathrm{N}$, Khan NH: Obstetric causes of stillbirth at low socioeconomic settings. J Pak Med Assoc 2009, 59(11):744-747.

doi:10.1186/1471-2458-11-S3-S6

Cite this article as: Jabeen et al:: Impact of interventions to prevent and manage preeclampsia and eclampsia on stillbirths. BMC Public Health 2011 11(Suppl 3):S6.

\section{Submit your next manuscript to BioMed Central and take full advantage of:}

- Convenient online submission

- Thorough peer review

- No space constraints or color figure charges

- Immediate publication on acceptance

- Inclusion in PubMed, CAS, Scopus and Google Scholar

- Research which is freely available for redistribution

Submit your manuscript at www.biomedcentral.com/submit 